\title{
The Effect of Temperature and Carbonyl Sulphide on Carbon Deposition on 20Cr25Ni Stainless Steel
}

\author{
Mary Taylor $^{1} \cdot$ Hugh Evans ${ }^{1} \cdot$ Peter Smith $^{1,2}$ • \\ Rengen Ding ${ }^{1} \cdot$ Yu Lung Chiu ${ }^{1}$ - Subash Rai ${ }^{1}$. \\ Brian Connolly ${ }^{1,3} \cdot$ Neal Smith $^{4} \cdot$ Lesley Pearson $^{4}$. \\ Clive Mowforth ${ }^{4}$
}

Received: 9 January 2017/Published online: 7 February 2017

(C) The Author(s) 2017. This article is published with open access at Springerlink.com

\begin{abstract}
In this paper, the results of a systematic study of the effect of temperature and $\mathrm{COS}$ concentration on the formation of carbon deposits on a $20 \mathrm{Cr} 25 \mathrm{Ni}$ austenitic stainless steel under a depositing gas of $1000 \mathrm{vppm}$ ethene in $1 \% \mathrm{CO} / \mathrm{CO}_{2}$ have been presented. Carbon deposits were found over the temperature range of 550-725 ${ }^{\circ} \mathrm{C}$ after $4 \mathrm{~h}$ exposure. $\mathrm{COS}$ additions to the ethene-bearing gas inhibited
\end{abstract}

Mary Taylor

M.P.Taylor@bham.ac.uk

Hugh Evans

H.E.Evans@bham.ac.uk

Rengen Ding

R.Ding@bham.ac.uk

Yu Lung Chiu

Y.L.Chiu@bham.ac.uk

Subash Rai

SXR347@bham.ac.uk

Brian Connolly

B.J.Connolly@bham.ac.uk

Neal Smith

Neal.Smith@edf-energy.com

Lesley Pearson

Lesley.Pearson@edf-energy.com

Clive Mowforth

Clive.Mowforth@edf-energy.com

1 University of Birmingham, Edgbaston, Birmingham B15 2TT, UK

2 Present Address: Rolls Royce Marine, Derby, UK

3 Present Address: University of Manchester, Manchester M13 9PL, UK

4 EDF Energy, Barnwood, Gloucester, UK 
the deposition process, but the effect was concentration and temperature dependent. The results have been interpreted in terms of the oxidation process and the adsorption of sulphur on the catalytic Ni-rich particles.

Keywords Stainless steel · Carbon deposition · COS · Carbon inhibition

\section{Introduction}

The formation of filamentary carbon deposits onto surfaces has been studied for a number of years, often been driven by the need to prevent the process occurring, e.g. in chemical or nuclear plant [1-3]. A number of reviews and proposed mechanisms have been published [3-7]. The application of relevance here is that occurring in nuclear plant where filamentary carbon deposits form on the surface of $20 \mathrm{Cr} 25 \mathrm{Ni}$ $\mathrm{Nb}$-stabilised stainless steel fuel cladding in Advanced Gas-cooled Reactors (AGRs). The morphology of the carbon deposits can vary from amorphous to graphite [4]. It has been established that the process of filamentary carbon formation on the $20 \mathrm{Cr} 25 \mathrm{Ni}$ steel of relevance here is catalysed by $\mathrm{Ni}$ or Ni-rich metallic particles of the order of $10 \mathrm{~s}$ of nanometre in size, [6-9]. The size and the composition of the particles are crucial parameters [7-13]. Powders, of controlled composition and size range, have been used to demonstrate and quantify the reactions occurring under a variety of depositing and non-depositing conditions $[3,10]$. Some of this work demonstrated the sensitivity of the catalytic process to the composition of binary alloys, with the catalytic nature of the particles being radically changed over, in some instances, very small compositional ranges [10, 13]. In this application, nickel-rich particles originating from the alloy have been identified as the catalyst and are termed intrinsic catalysts [7, 8]. Austenitic particles have also been reported in the metal dusting process [14] although the environment for that mechanism differs to the case considered here. In dusting, the particles are formed as part of the disintegration of the alloy. Here, the particles form as a result of the internal oxidation of the surface region of the alloy. Understanding of the processes involved in the deposition of carbon is essential for inhibiting the process.

\section{Background}

A series of tests was conducted using purpose built rigs, designed so as to eliminate any extraneous sources of catalysis and bring a robust level of control in the experimental approach. The depositing gas used was pre-mixed and had a nominal composition of 1000 vppm $\mathrm{C}_{2} \mathrm{H}_{4}$ with $1 \% \mathrm{CO}$ and balance $\mathrm{CO}_{2}$. It has been established $[8,9]$ that the reaction dominating the oxygen potential of this gas mixture is:

$$
2 \mathrm{CO}+\mathrm{O}_{2} \leftrightarrow 2 \mathrm{CO}_{2}
$$

Equating to a $\mathrm{pO}_{2}$ of approximately $10^{-23}$. The ethene dissociation reaction that dominates was identified as $[8,9]$ : 


$$
\mathrm{C}_{2} \mathrm{H}_{4}+2 \mathrm{CO}=4 \mathrm{C}+2 \mathrm{H}_{2} \mathrm{O}
$$

Under the conditions existing in this gas mixture, it has been shown that the iron and chromium constituents of the steel will oxidise and that nickel will not, and the carbon activity lay in the approximate range $10^{2}<a_{c}<10^{7}$, i.e. values greater than unity $[8,9]$.

As already stated, the presence of a catalyst is a critical factor in the carbon deposition process. A mechanism leading to the formation of metallic particles originating from the clad alloy used in AGR reactors was proposed [8]. The metallic particles form within an internal oxidation layer, as the surrounding chromium and iron elements oxidise the metallic nickel concentrate into particles. On contact with the gas the particles catalyse the carbon deposition process. Particles of the order of $10 \mathrm{~s}$ of nanometres were found encased in carbon at the tips of fibres. TEM examination was used to identify the composition of the particles which were found to be metallic nickel [8]. A similarity between the structure of the nickel crystals and the stacking of the carbon layers in the vicinity of the particles was revealed. This implied that there was a direct relationship between the crystallographic structure of the particle and the carbon layer formation.

Once a mechanism leading to the formation of the catalytic particles had been established, it was then possible to investigate methods of inhibiting or reducing the catalytic effect. Samples of the alloy were subjected to pre-oxidation of the surface under very low $\mathrm{pO}_{2}$ environments with a small concentration of $\mathrm{H}_{2} \mathrm{O}$ resulting in the formation of a slow growing, surface oxide of pure chromia across the whole surface [8]. This proved an effective method for suppressing the formation of the catalyst sealing the surface with a protective oxide.

An extension of this approach involved minor additions of silicon to the alloy [8]: known to promote early formation of a protective, defect-free chromia on austenitic steels $[15,16]$. An alternative approach to suppression of carbon deposition involved changing the chemistry of the particles. This was achieved by increasing the oxygen potential of the depositing gas [9] or by the introduction of sulphur species into the depositing gas $[15,17]$. Both of these routes are thermodynamically plausible; the former produces an environment in which nickel oxidises thus preventing metallic particle formation, the later does not prevent the formation of the particles but modifies the catalytic nature. Two processes whereby carbon suppression could be achieved via the later route were postulated. One proposed that the particles formed as nickel sulphide and not as the metallic alternative. The crystal structure and lattice spacings of the sulphide differ significantly to the metallic counterpart which, as indicated earlier, is influential in the structure of the resultant carbon layer stacking. Another possibility was poisoning of the surface of the particles by the preferential adsorption of sulphur. Determination as to which, if either, of these possibilities occurred in this system was not confirmed in the earlier work due to the difficulty in isolating sufficient numbers of particles and the difficulty in resolving extremely thin sulphide layers or poisoned surfaces. It should be noted that no nickel sulphides were detected during the course of the investigations and thus it was postulated that surface poisoning was the most likely route to the suppression of filamentary carbon formation [15]. 
Much of the earlier work was conducted at $550{ }^{\circ} \mathrm{C}[8,9,15,16]$. The nominal composition of the pre-mixed gas used in that work was 1000 vppm $\mathrm{C}_{2} \mathrm{H}_{4}$ in $1 \% \mathrm{CO}$ balance $\mathrm{CO}_{2}$, and the alloy was a $20 \mathrm{Cr} 25 \mathrm{Ni} \mathrm{Nb}$-stabilised austenitic stainless steel. The concentration of the COS added to the gas mixture was approximately 240 vppb. In this paper, the results over an extended temperature range will be presented, i.e. $500-725^{\circ} \mathrm{C}$. The same nominal gas composition has been used, but COS concentrations have also been extended up to $1460 \mathrm{vppb}$. The effect of temperature and gas composition on the deposition process will be presented.

\section{Experimental Procedures}

The alloy used was a stabilised austenitic steel of composition 20.0Cr, 25.0Ni, $53.1 \mathrm{Fe}, 0.7 \mathrm{Nb}$ and $0.6 \mathrm{Mn} w \mathrm{t} \%$ and was available as cold-worked strip. The nominal composition of depositing gas was 1000 vppm $\mathrm{C}_{2} \mathrm{H}_{4}$ in $1 \% \mathrm{CO}$ with a balance of $\mathrm{CO}_{2}$ gases and was supplied as a pre-mixed gas by BOC. The concentration of the ethene ranged from 1010 to $1020 \mathrm{vppm}$ and the $\mathrm{CO}$ ranged from 0.97 to $1.01 \%$. The composition of the gases was added to carbonyl sulphide and is given in Table 1. An inert gas of $5 \% \mathrm{H}_{2}$ in Ar was used to purge the rig prior to and after exposure.

Approximately $0.6 \mathrm{~mm}$ thick cold rolled strip of the alloy was sectioned into samples of approximately 10 by $20 \mathrm{~mm}$. The cold rolled surfaces were removed to a depth of approximately $50 \mu \mathrm{m}$ using conventional grinding on SiC paper of grit sizes 240-1200 with water as a lubricant. Polishing was performed using 6 and $1 \mu \mathrm{m}$ diamond with a water based lubricant. Early samples were electro-polished in $10 \%$ perchloric acid in acetic acid, but this was replaced later on in the study by polishing using a silica sol. No difference was seen in the carbon deposition process using either of these final stage preparation techniques. All samples were subjected to a final ultrasonic cleaning in ethanol and annealed in an inert atmosphere for $30 \mathrm{~min}$ at $930{ }^{\circ} \mathrm{C}$ to reduce the residual stresses and to create a microstructure consisting of grains of between 3 and $10 \mu \mathrm{m}$.

The deposition tests were performed in a dedicated rig consisting of two furnaces in series with copper pipes connecting to gas cylinders and extraction. The first furnace contained titanium foil, to ensure that the residual oxygen in the pre-mixed gas bottles was removed and thus achieving the very low oxygen partial pressure necessary for the carbon deposition process. An alloy sample was ultrasonically

Table 1 Composition of the COS bearing gases

\begin{tabular}{llll}
\hline $\mathrm{CO} \%$ & $\mathrm{C}_{2} \mathrm{H}_{4} / \mathrm{vppm}$ & $\mathrm{COS} / \mathrm{vppb}$ & $\mathrm{CO}_{2}$ \\
\hline 0.98 & 1016 & 113 & bal. \\
0.99 & 1064 & 234 & bal. \\
1.00 & 1032 & 513 & bal. \\
1.03 & 1095 & 606 & bal. \\
1.05 & 1055 & 763 & bal. \\
0.96 & 978 & 1040 & bal. \\
0.95 & 1033 & 1460 & bal. \\
\hline
\end{tabular}


cleaned in ethanol and positioned upright in an alumina boat ensuring maximum contact between the surface of the sample and the flowing gas. Also included was a piece of cold rolled $99.99 \%$ purity nickel of similar dimensions, this was positioned behind the alloy sample in the gas flow to prevent any carbon nucleated on the nickel transferring to the sample. No surface preparation other than ultrasonic cleaning in ethanol was performed on the nickel. The alumina boat, with samples, was placed in the second furnace.

The rig was made gas tight and the system purged with an inert gas of 5\% hydrogen in argon for 2 hours. The first furnace, containing the titanium foil, was brought up to $700{ }^{\circ} \mathrm{C}$ at a heating rate of $20{ }^{\circ} \mathrm{C} \mathrm{min}{ }^{-1}$. After $1 \mathrm{~h}$, the second furnace was brought up to the test temperature, again at a rate of $20^{\circ} \mathrm{C} \min ^{-1}$. After a further hour, the gas was swapped to the test gas. The test was run for $4 \mathrm{~h}$ after which time the gas was swapped back to the inert gas and the furnaces switched off in sequence and allowed to cool to room temperature over night. The examination was conducted as soon after testing as possible to minimise disruption of the deposits or contamination. The temperature range over which testing was conducted was $500-725^{\circ} \mathrm{C}$. The exposure time at each temperature was constant at $4 \mathrm{~h}$, and the gas flow was approximately $0.31 \mathrm{~min}^{-1}$ at 1 atmosphere pressure.

After a deposition run the alloy and nickel samples were positioned onto an aluminium SEM stub using a conductive tape such that the surfaces facing the gas flow were uppermost. A field emission gun, FEG-SEM, capable of imaging $10 \mathrm{~nm}$ features and fitted with Energy-Dispersive Spectroscopy (EDS) and Wavelength Dispersive Spectroscopy (WDS), was used to examine the surface of the samples after deposition and obtain comparative compositional values for the assessment of carbon deposits. Both EDS and WDS were utilised to confirm the composition of the alloy and to confirm the presence or otherwise of carbon. WDS was particularly useful in the analysis of oxygen and carbon. Background levels of carbon were determined from untested clean samples of both the alloy and $99.99 \%$ purity nickel. Focused Ion Beam (FIB) milling was used to perform a series of cross sections at $200 \mathrm{~nm}$ intervals to investigate the relationship between the filamentary carbon deposits and sub-surface features.

\section{Results and Discussion}

\section{Effect of Temperature}

Filamentary carbon deposits were observed on the surfaces of the samples tested over the temperature range $550-725^{\circ} \mathrm{C}$, Fig. 1 , in the absence of COS. No carbon was detected on the samples exposure at $500{ }^{\circ} \mathrm{C}$, probably due to the slow oxidation kinetics with insufficient time for catalyst formation. Examination of the nickel samples accompanying these tests demonstrated that nickel oxides had not formed and thus verified that low $\mathrm{pO}_{2}$ conditions had been achieved. Comparison to the earlier work [7-9] showed excellent agreement between the morphology and distribution of carbon coverage at $550{ }^{\circ} \mathrm{C}$. Quantification of the amount of carbon deposition that occurred with increasing temperature was attempted using 60 by 


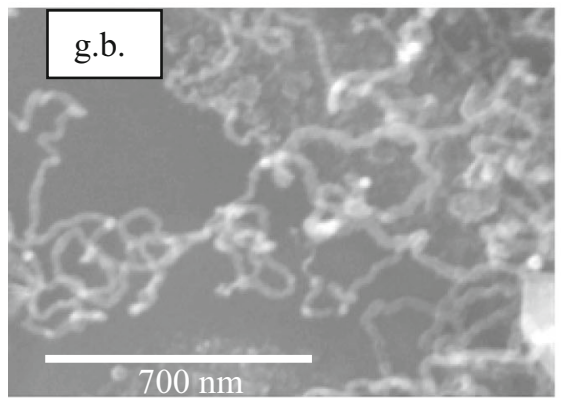

(a) $550^{\circ} \mathrm{C}$

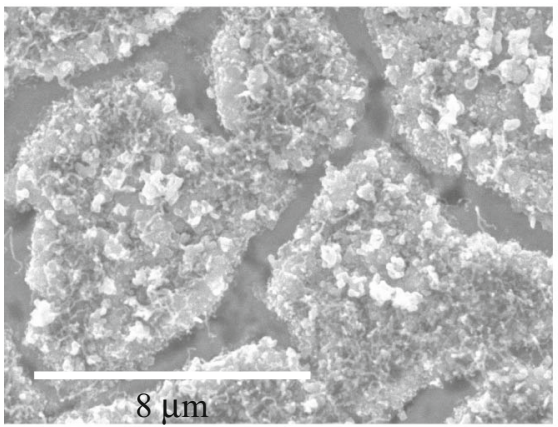

(c) $650^{\circ} \mathrm{C}$

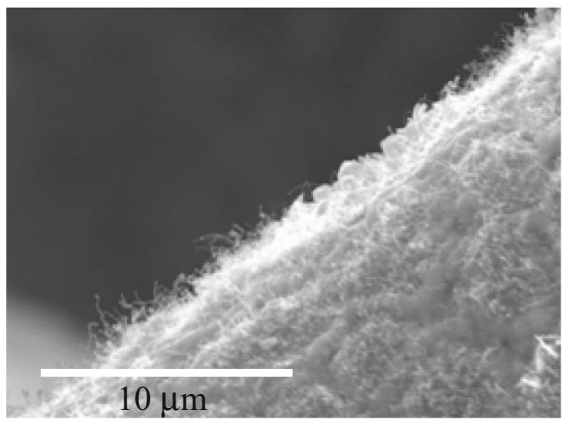

(e) $700^{\circ} \mathrm{C}$

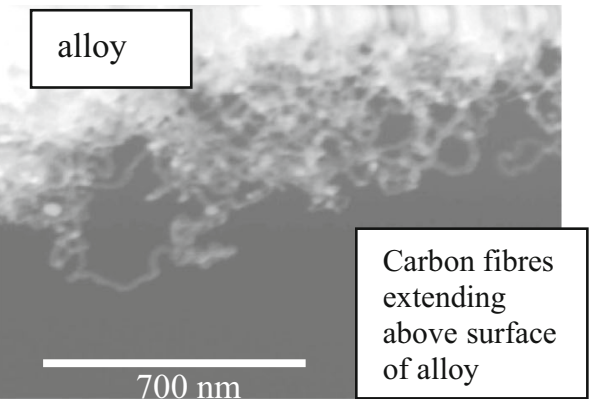

(b) $550^{\circ} \mathrm{C}$

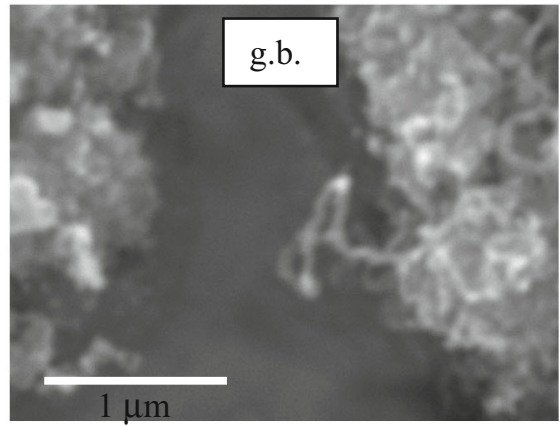

(d) $650^{\circ} \mathrm{C}$

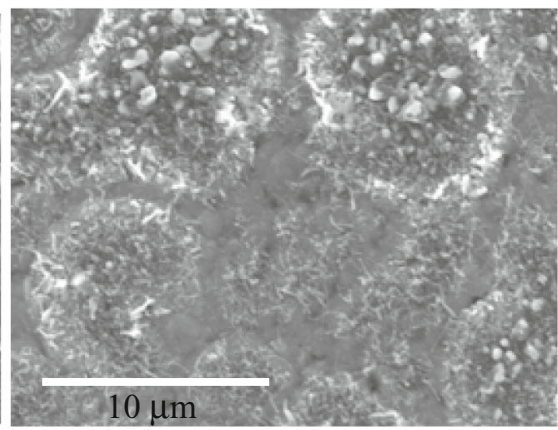

(f) $700^{\circ} \mathrm{C}$

Fig. 1 SEM images of the surface of samples of alloy exposed for four hours to the depositing gas at a and b $550{ }^{\circ} \mathrm{C}$, c and $\mathbf{d ~} 650{ }^{\circ} \mathrm{C}$ and e and f $700{ }^{\circ} \mathrm{C}$, showing filamentary carbon distributed over the surface of the samples, grain boundaries (g.b.) were locations where carbon deposits were not produced

$40 \mu \mathrm{m}$ EDS area scans. Although not quantitative this did show an increase in carbon present with increasing temperatures. Values of approximately 20 at.\% above background levels were found at 550 and $600{ }^{\circ} \mathrm{C}$ rising to 30 at. $\%$ at 675 and 35 at. $\%$ at $700{ }^{\circ} \mathrm{C}$.

The distribution of carbon across the surface of the samples also followed that found in the earlier studies, i.e. no carbon fibres were found at grain boundaries where early formation of a surface chromia layer occurs [8] but did form at the 
Fig. 2 TEM image of a nano particle within a carbon fibre produced during exposure at $600{ }^{\circ} \mathrm{C}$ for $4 \mathrm{~h}$ in a COS-free deposition gas. Diffraction patterns showed the composition of the particle to be nickel

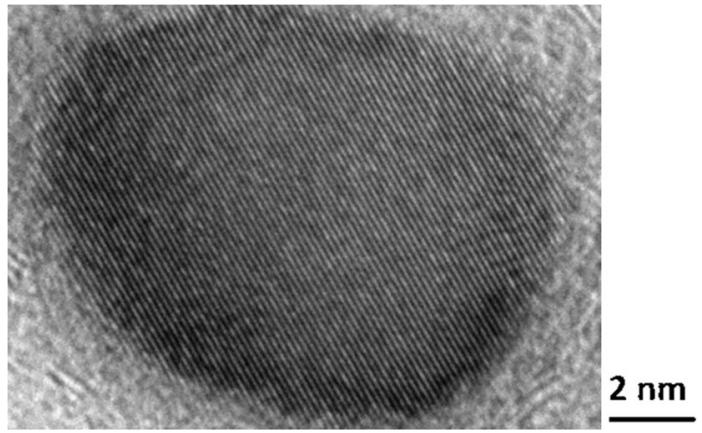

centre of grains, Fig. 1. The chromia grows laterally from these boundaries with increasing time at temperature. These sites do permit the examination of fibres that fall across them, Fig. 1a, d. Over the centre of grains, dense tangles of carbon fibres extend above the samples, Fig. 1b, e. In these images, bright contrast features within the carbon fibre can be observed. Some particles, encased in carbon, have been isolated and examined using TEM, Fig. 2. These nanometre-sized particles have been identified as nickel by the diffraction patterns obtained.

A series of FIB sections were made from a sample held at $650{ }^{\circ} \mathrm{C}$, Fig. 3. From this investigation, it was clear that at grain boundaries there was a thin surface oxide extending approximately $1 \mu \mathrm{m}$ laterally into the grain centre. Filamentary carbon deposits were clearly visible in dark contrast within the tungsten layer applied to the surface of the sample for protection during the FIB process. Tracking through the sections, it was possible to confirm that the sites of greatest filamentary carbon deposits were associated with sub-surface internal oxidation, Fig. 3. This evidence supports the mechanism described earlier [8] that the source of the catalytic particles responsible for the formation of filamentary carbon deposits in this alloy is due to the selective, internal oxidation process in the environment where the $\mathrm{pO}_{2}$ is below that required to oxidise nickel. Additional, it has been observed that other blocky features formed on the surface of the samples during exposure. These have been identified as iron oxides, often running in a band adjacent to the grain boundaries and also nickel-rich without any associated oxygen EDS signal. The presence of metallic nickel at the surface also confirms that the gaseous environment has a $\mathrm{pO}_{2}$ at a level where nickel oxides do not form.

\section{Effect of COS}

As carbon deposition was not achieved at $500{ }^{\circ} \mathrm{C}$, no further testing was performed at this temperature. SEM images of the surfaces of selected samples exposed at a range of temperatures and COS concentrations are shown in Fig. 4.

The results at $550{ }^{\circ} \mathrm{C}$ confirmed the findings of the previous study [15] in that no filamentary carbon was deposited on the surface of the alloy with gases containing 234 vppb COS, Fig. 4a. In this study, the lower concentration of 113 vppb COS also 


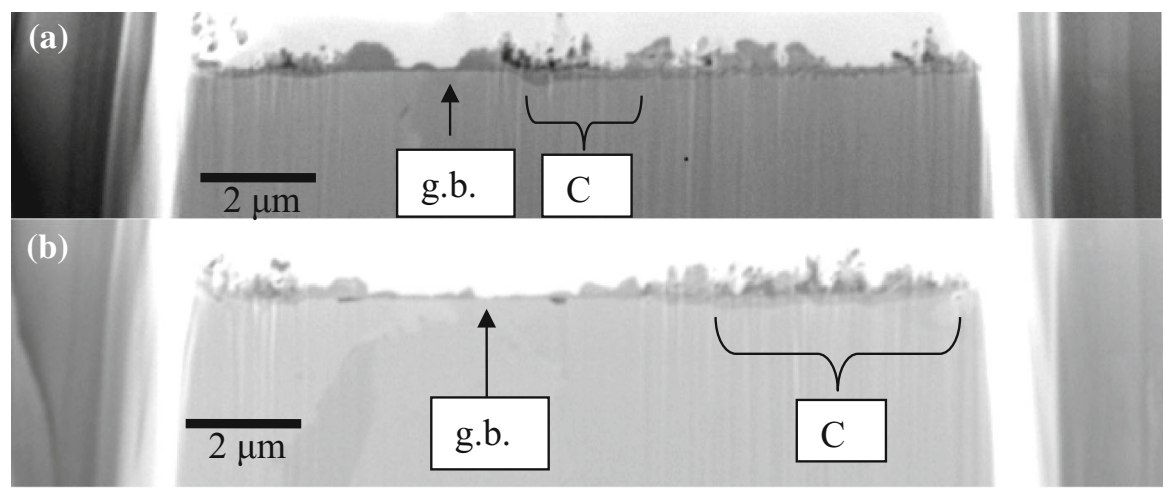

Fig. 3 SEM images of two slices through the sample held in the depositing environment at $650{ }^{\circ} \mathrm{C}$ showing $\mathbf{a}$ a section of the grain through a grain and $\mathbf{b}$ a section including an extensive grain boundary region. Both sites show a thin oxide at the grain boundaries (g.b.) and regions of thicker oxide growth with carbon deposits (C)

resulted in complete inhibition of filamentary carbon formation at $550{ }^{\circ} \mathrm{C}$. Carbon deposition was also inhibited with $513 \mathrm{vppm}$ at $650{ }^{\circ} \mathrm{C}$ Fig. $4 \mathrm{c}$.

The criteria used to assess complete inhibition of carbon deposition included FEGSEM inspection of the surface of the samples and EDS and WDS analysis. Due to the natural occurrence of carbon in the environment background, readings were taken from clean, unexposed sections of a nickel sample. A positive carbon reading was recorded where the concentration of carbon on the sample was greater than the back ground readings. Complete inhibition of the filamentary carbon deposition process was considered to occur when no obvious filamentary carbon was observed and where no carbon above background levels was detected with EDS or WDS. The findings have been summarised in Fig. 5. Here, solid black symbols indicate where carbon concentrations were above background levels and fibres were observed, and open symbols where neither fibres nor above background carbon concentrations were recorded. It should be noted that repeat tests were conducted at all test conditions and that tests using depositing gas, i.e. 0 vppb COS, were performed intermittently to check the proper function of the rig and to eliminate any concerns regarding contamination of the pipe work.

The plot in Fig. 5 shows that as the temperature increased the concentration of $\mathrm{COS}$ necessary to achieve complete inhibition also increased. At $675^{\circ} \mathrm{C}$ complete inhibition was eventually achieved with a gas containing 1460 vppb COS but this was not achieved at 700 or $725^{\circ} \mathrm{C}$. Interestingly, the testing conducted at the higher temperatures showed that the morphology of the carbon fibre changed with increasing COS concentration, Fig. 4b. The fibres appeared to be thicker and a distinctive globule formed at the tip. EDS and WDS analysis of the globule to provide information on the structure and composition, i.e. whether a metallic particle was encapsulated within the carbon, proved inconclusive. The fibres also seemed shorter than those formed in the COS-free environments, Fig. 1d. The dense tangle of thin fibres seen with the COS-free gas were no longer present. Thus, 


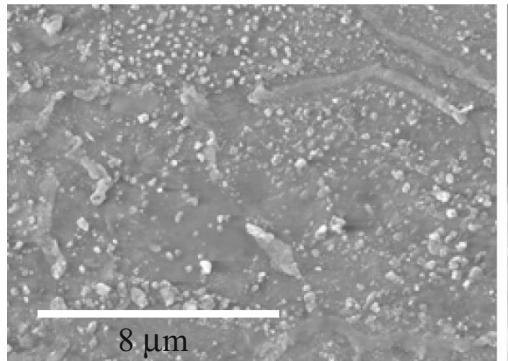

(a) $550^{\circ} \mathrm{C} / 234 \mathrm{vppb} \mathrm{COS}$.

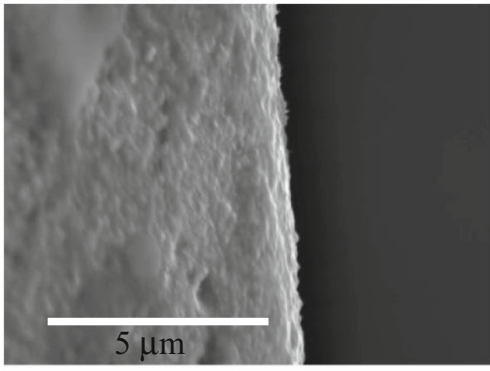

(c) $650^{\circ} \mathrm{C} / 513 \mathrm{vppb} \mathrm{COS}$

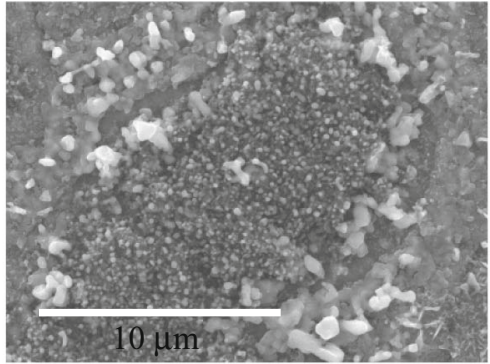

(e) $700^{\circ} \mathrm{C} / 606 \mathrm{vppb} \mathrm{COS}$.

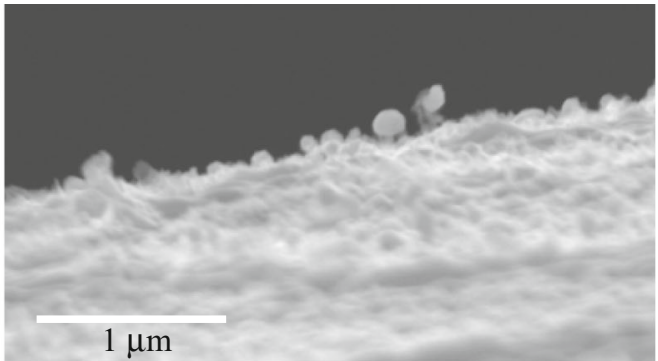

(b) $650^{\circ} \mathrm{C} / 234 \mathrm{vppb} \mathrm{COS}$.

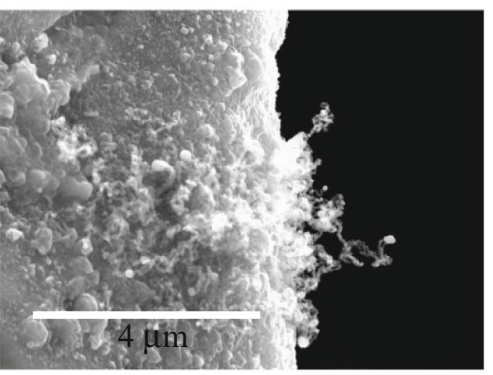

(d) $700^{\circ} \mathrm{C} / 513 \mathrm{vppb} \mathrm{COS}$.

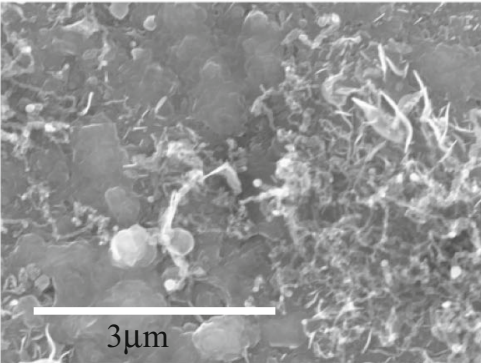

(f) $700^{\circ} \mathrm{C} / 763 \mathrm{vppb} \mathrm{COS}$.

Fig. 4 SEM images of the surface of samples of alloy exposed for four hours to the COS containing depositing gas at a $513{ }^{\circ} \mathrm{C} / 240 \mathrm{vppb} \operatorname{COS}, \mathbf{b} 650{ }^{\circ} \mathrm{C} 234 \mathrm{vppb} \mathrm{COS}$ showing some carbon filaments extending above the surface, $\mathbf{c} 650{ }^{\circ} \mathrm{C} / 513 \mathrm{vppb} \operatorname{COS}, \mathbf{d} 700{ }^{\circ} \mathrm{C} / 513 \mathrm{vppb}, \mathbf{e} 700{ }^{\circ} \mathrm{C} / 606 \mathrm{vppb} \mathrm{COS}$ with some carbon deposits but lying close to the surface, and $\mathbf{f} 700{ }^{\circ} \mathrm{C} / 763 \mathrm{vppb} \mathrm{COS}$ showing reduced carbon deposits

the introduction of COS into the gas was clearly modifying the formation of carbon fibres under these test conditions.

One purpose of this investigation was to define where inhibition of the filamentary carbon deposition process occurred as a function of temperature and COS concentration. Taking this approach and assuming an Arrhenius relationship, the following was obtained:

$$
[\mathrm{COS}]=23.786 \times 10^{9} \exp \left(\frac{-16345.1}{T}\right)
$$




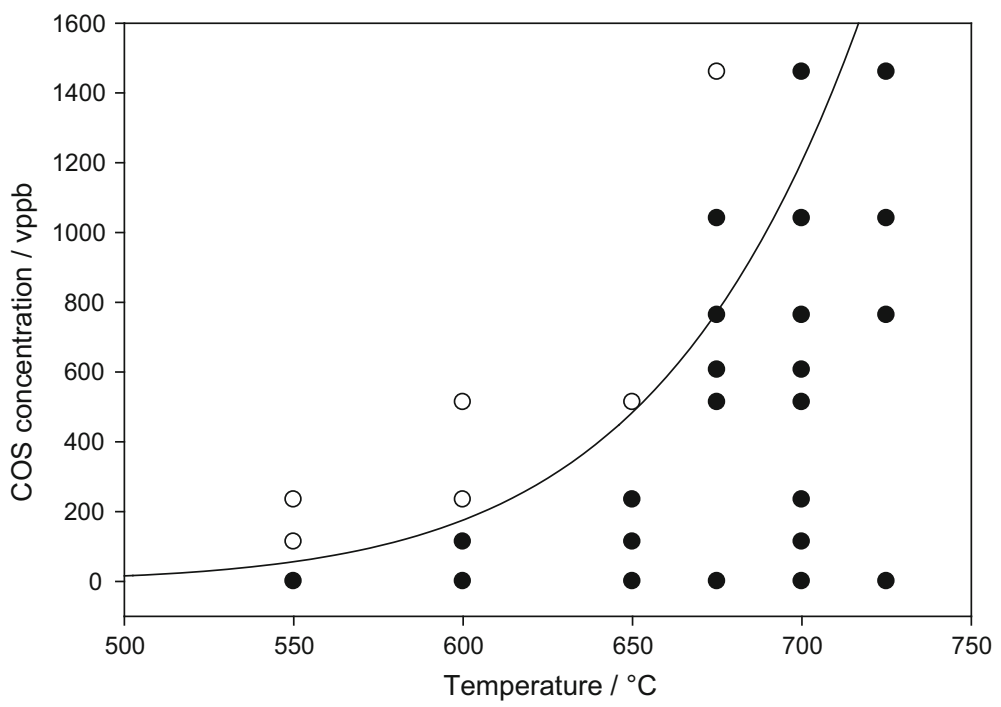

Fig. 5 Plot of the temperature versus [COS] matrix showing tests where filamentary carbon deposits were recorded, solid symbols, and where no carbon was detected, open symbols. The line is a plot of Eq. (3)

where $\mathrm{T}$ is temperature in Kelvin and $[\mathrm{COS}]$ is the COS concentration in vppb. This is plotted on Fig. 5 as a solid line. A good match to the inhibition process is found up to $650{ }^{\circ} \mathrm{C}$ but is less good at the higher temperatures. Further refinements to this model are ongoing. This approach produces a binding energy for sulphur on nickel of $16,345 \mathrm{~J} \mathrm{~mol}^{-1}$. This compares well to calculations where a value of $18,380 \mathrm{~J} \mathrm{~mol}^{-1}$ was obtained for $80 \%$ surface coverage by sulphur [17].

Two proposed mechanisms for the effect of COS are: the formation of nickel sulphide or poisoning of the surface of the particles. Information available in the literature shows that the free energy of adsorptions of sulphur on a metal is lower than that for the formation of a stable sulphide [13, 17-20]. Much of the work available in the literature has been conducted where the sulphur species originates from $\mathrm{H}_{2} \mathrm{~S}$. The information provided is, however, relevant to the low oxygen partial pressures experienced in the conditions in this research. A review containing gases where the sulphur present was derived from a number of sources including COS is provided in reference 20 and an extensive review by Bartholomew describes the mechanism of sulphur poisoning [20].

Calculations of minimum COS concentrations in equilibrium with nickel and nickel sulphide give values of approximately 430 and $870 \mathrm{vppb}$ at 577 and $677{ }^{\circ} \mathrm{C}$, respectively [17]. Thus, the concentrations of COS used here are too low for nickel sulphide formation. In the same work, concentrations necessary for poisoning of nickel, with a sulphur coverage of $80 \%$, were calculated as 100 and $710 \mathrm{vppb}$ at the same conditions. These concentrations are close to the values found in this work. Further work is continuing to identify whether poisoning is occurring but no nickel sulphides have been found to-date. 


\section{Conclusion}

A mechanism linking the oxidation processes occurring in the $20 \mathrm{Cr}: 25 \mathrm{Ni}$ niobium stabilised austenitic steel under environments of low $\mathrm{pO}_{2}$ to the formation of catalytic nickel particles has been further developed in this research programme. The link to the oxidation processes was further emphasised by the lack of deposition occurring at $500{ }^{\circ} \mathrm{C}$ and the extensive deposits seen on samples exposed at the higher temperatures. All tests were verified by repeat testing. The role of sulphur as a means of inhibiting filamentary carbon formation was investigated up to COS concentrations of $1460 \mathrm{vppb}$. Complete inhibition was observed at temperatures below $675{ }^{\circ} \mathrm{C}$. At higher temperatures, i.e. 700 and $725^{\circ} \mathrm{C}$, inhibition was not achieved but examination of these samples did show modification to the morphology of the carbon fibres. Using a criterion of complete inhibition of the deposition process, it has been possible to provide a formula to predict the concentration of COS necessary to inhibit filamentary carbon deposition over the temperature range $500-725{ }^{\circ} \mathrm{C}$. Thermodynamic evidence supports the theory that adsorption and thus poisoning of the surfaces of the catalytic particles, is the most likely process by which the inhibition is occurring. Further work is being conducted to investigate this phenomenon.

Acknowledgements The authors thank the support provided by the Electron Microscopy Centre at the University of Birmingham. Limitation of liability - Whilst EDF Energy Nuclear Generation Ltd believes that the information given in this document is correct at the date of publication it does not guarantee that this is so, nor that the information is suitable for any particular purpose. Users must therefore satisfy themselves as to the suitability of the information for the purpose for which they require it and must make all checks they deem necessary to verify the accuracy thereof. EDF Energy Nuclear Generation Ltd shall not be liable for any loss or damage (except for death or personal injury caused by negligence) arising from any use to which the information is put.

Open Access This article is distributed under the terms of the Creative Commons Attribution 4.0 International License (http://creativecommons.org/licenses/by/4.0/), which permits unrestricted use, distribution, and reproduction in any medium, provided you give appropriate credit to the original author(s) and the source, provide a link to the Creative Commons license, and indicate if changes were made.

\section{References}

1. M. J. Bennett and J. B. Price, Journal of Material Science 16, 1981 (170).

2. T. I. Barry and A. T. Dinsdale, Material Science and Technology 10, 1994 (1090).

3. R. T. K. Baker, Carbon 27, (3), 1989 (315-323).

4. T. Baird, J. R. Fryer and B. Grant, Carbon 12, 1974 (591-602).

5. A. Oberlin, M. Endo and T. Koyama, Journal of Crystal Growth 32, (3), 1976 (335-349).

6. P. A. Tesner, E. Y. Robinovich, I. S. Rafalkes and E. F. Arefieva, Carbon 8, 1970 (435-442).

7. G. R. Millward, M. Aindow and H. E. Evans, in The Nucleation Phase of Carbon Deposition on AGR Fuel-Pin Surfaces. University of Birmingham technical report, IMC reference: FC/AGR/5028, April 1999.

8. G. R. Millward, H. E. Evans, M. Aindow and C. W. Mowforth, Oxidation of Metals 56, (3/4), 2001 (231). 
9. G. R. Millward, H. E. Evans, I. P. Jones and C. D. Eley, Materials at High Temperatures 20, 2003 (535).

10. C. Park and R. T. K. Baker, Journal of Catalysis 190, 2000 (104-117).

11. M. S. Kim, N. M. Rodriguez and R. T. K. Baker, Journal of Catalysis 134, 1992 (253-268).

12. V. Z. Mordkovich, E. A. Dolgova, A. R. Karaeva, D. N. Kharitonov, I. A. Maslov, A. A. Kamenev and V. F. Tretjakov, Carbon 45, 2007 (62-69).

13. J.-H. Wang and M. Liu, Electrochemistry Communications 9, 2007 (2212-2217).

14. D. J. Young, J. Zhang, C. Geers and M. Schuetze, Materials and Corrosion 62, (1), 2011 (7-28).

15. G. R. Millward, H. E. Evans, I. P. Jones, C. D. Eley and C. W. Mowforth, Materials and Corrosion 54, (11), 2003 (864-869).

16. R. C. Lobb, J. A. Sasse and H. E. Evans, Materials Science and Technology 5, 1989 (828-834).

17. Technical Report 'Sulphur Adsorption and Speciation Effects in AGR Coolant', EDF Energy Generation, internal report.

18. J. G. McCarty and H. Wise, Journal of Chemical Physics 72, (12), 1980 (6332-6337).

19. K. K. Pandey, Coordination Chemistry Reviews 140, 1995 (37-114).

20. C. H. Bartholomew, Applied Catalysis A General 212, 2001 (17-60). 